\title{
RELABELLING: A MAJOR PROCESS IN LANGUAGE CONTACT ${ }^{1}$
}

\author{
Claire Lefebvre \\ Université du Québec à Montréal
}

\section{Introduction}

The problem of language contact may be taken up from two opposite angles: the processes at work in language contact situations, or, ignoring the processes, the language contact varieties. In this paper, I look at contact phenomena from the former rather than from the latter angle. I focus on one process: relabelling. Relabelling is a mental operation that consists in assigning a lexical entry of a given language, $\mathrm{L}_{1}$, a new label taken from another language, $\mathrm{L}_{2}$ (see below).

The importance of relabelling in language contact has been greatly underestimated. This is due to the fact that this process is referred to in the literature by a number of terms that hide its unity and prominence in language contact situations. Section 1 of the paper is dedicated to assessing the extent of relabelling across language contact situations. I provide an overview of the various terms used in the literature to refer to the process that I refer to as 'relabelling'. Having done this, it becomes possible to assess the extent of relabelling across various types of language contact situations.

Language varieties that have involved relabelling do not all look the same. In section 2, I show that this is due to the variable extent of relabelling across lexicons, which, in turn, is determined by a number of factors that define the situations in which this process is used. These factors include the number of languages involved, the amount of access to $\mathrm{L}_{2}$, whether code switching is involved, and whether language shift is involved.

The third part of the paper addresses the question of whether relabelling can apply in the case of agglutinative languages. The discussion of this case on the basis of relevant data sheds new light on relabelling.

\footnotetext{
${ }^{1}$ A preliminary version of this paper was presented at the Symposium on 'Language Contact and Dynamics of Language: Theory and Implications', held at the Max Planck Institute for Evolutionary Anthropology, Leipzig, May 10-13, 2007. I would like to thank the participants in the symposium, as well as the reviewers, for their comments and questions, which contributed to shaping the final version of this paper. I am grateful to SSHRCC for financing the research underlying this paper, to Zofia Laubitz for editing the manuscript, and to Andrée Bélanger for formatting it.
} 


\section{Assessing the extent of relabelling across language contact situations}

The aim of this section is to assess the extent of relabelling across language contact situations. I begin with a survey of the literature, focusing on the terms used to refer either to the process that I refer to as relabelling or to its results.

\subsection{The vocabulary issue}

I will start by presenting a precise definition of the process of relabelling and of its results, with which the various terms found in the literature will be compared.

\subsubsection{Relabelling}

Relabelling can be represented as in 1. Given a lexical entry as in 1.a., assign this lexical entry a new phonological representation drawn from another language, as in 1.b., and eventually, remove the original phonological representation, yielding 1.c.

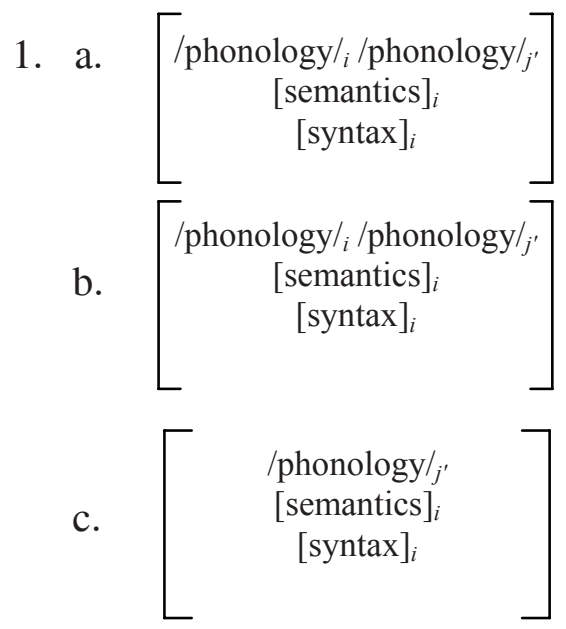

The new lexical entries so formed have the semantic and syntactic properties of the original ones and phonological representations derived from phonetic strings drawn from another language ${ }^{2}$. An example of a lexical entry formed by means of relabelling is provided in 2 . with data from Haitian Creole and its source languages.

2.

a.

$/$ hù $/{ }_{i}$

'to murder'

'to mutilate'

b.

\author{
/hù $/{ }_{i} \quad$ /ansasinen $_{j^{\prime}}(<$ Fr. assassiner 'to \\ murder') \\ 'to murder' \\ 'to mutilate'
}

FONGBE

FONGBE/ HAITIAN

\footnotetext{
${ }^{2}$ The phonological representation derived from another language is identified as $j^{\prime}$ rather than as $j$. The prime represents the fact that the new phonological form associated with a lexical entry is not that of language $j$, but rather a phonological form established on the basis of a phonetic form in language $j$ interpreted by the phonological principles of language $i$ (see, e.g., Brousseau \& Nikiema 2006; Steele \& Brousseau 2006).
} 
c.

$$
\begin{aligned}
& \text { /ansasinen/ }{ }^{\prime} \text { ' } \\
& \text { 'to murder' } \\
& \text { 'to mutilate' }
\end{aligned}
$$

HAITIAN

Relabelling is semantically driven, in that the two lexical entries that are associated in the process must share some semantics (see also Muysken 1981). The data in 2.b. show, however, that the two entries that are associated in the process need not be totally semantically congruent. While Fongbe hù means both 'to murder' and 'to mutilate', French assassiner means only 'to murder'. ${ }^{3}$ As a result of this constraint on relabelling, items that do not have any semantic content, such as case markers, operators, etc., do not undergo the process (for a detailed discussion of this issue, see Lefebvre 1998, chapter 2).

The remainder of this section is dedicated to showing that certain other terms used in the literature actually refer to the process described here as relabelling, or that the result of the process identified by another term corresponds to that of relabelling.

\subsubsection{Relexification as relabelling}

Muysken (1981:61) defines relexification as follows: 'Given the concept of lexical entry, relexification can be defined as the process of vocabulary substitution in which the only information adopted from the target language in the lexical entry is the phonological representation.' Relexification is represented in 3., adapted from Muysken.

3. SOURCE LANGUAGE

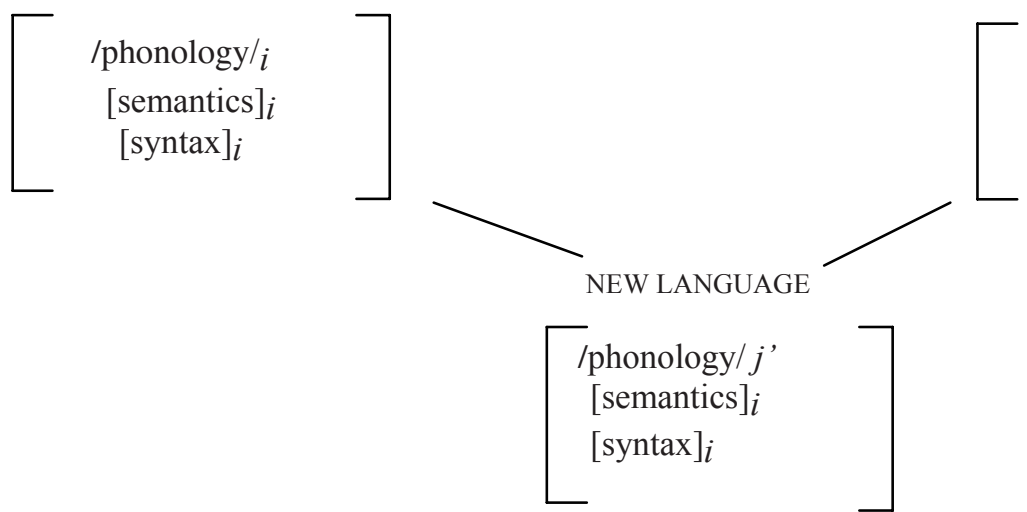

LEXIFIER LANGUAGE

$/$ phonology/j [semantics] $j$ $[\operatorname{syntax}] j$

The process is exemplified in 4., on the basis of the data in 2 .

\footnotetext{
${ }^{3}$ As is extensively discussed in Lefebvre (1998, chapter 2), in most cases where relabelling applies, the $\mathrm{L}_{2}$ learners do not have sufficient access to $\mathrm{L}_{2}$ to perceive/learn the properties (e.g., categorial, subcategorisation, etc.) of the target lexical entries. This is why the only property of the target lexical entry that is required for relabelling is partially shared semantics with the lexical entry to be relabelled. According to Lefebvre \& Lumsden (1994), this partial overlap is captured by $\mathrm{L}_{2}$ learners on the basis of the occurrence of lexical items in specific linguistic and pragmatic contexts.
} 
4. FONGBE

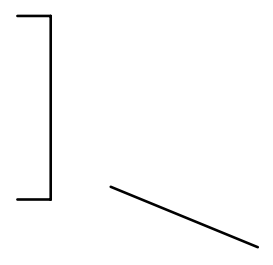

\section{HAITIAN}

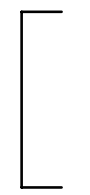

\section{/ansasinen/ $j^{\prime}$ \\ 'to murder' \\ 'to mutilate'}

FRENCH

/asasine/

'to murder'

According to this definition, relexification is a mental process that builds a new lexical entry by copying an existing lexical entry, and replacing its phonological representation with a representation derived from another language. The process in 4 . can be restated as relabelling in 1 . and the end result of relexification in 4. corresponds to that of relabelling in 2.c. Relexification thus reduces to relabelling. ${ }^{4}$

\subsubsection{Paralexification as paralabelling}

Mous (1995:1) identifies a cognitive process which he refers to as paralexification. This process provides a second phonological form for a given lexical entry. 'Paralexification is the addition of a word form to a lexical entry. This added form is on a par with the existent word form of the lexical entry in question. That is: two word forms share meaning, metaphorical extensions, and morphological properties such as noun class membership for nouns and predicate frame for verbs.' Mous's definition of paralexification can be schematised as in 5., where a given lexical entry has two phonological representations, the original one and a second one drawn from another language, but only one set of semantic and syntactic features.

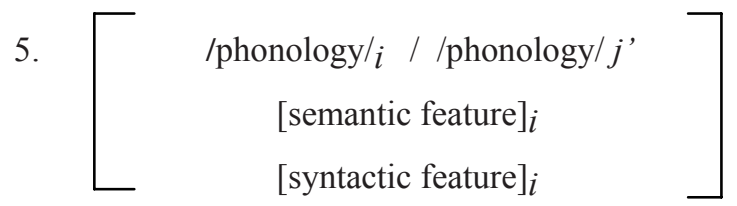

The process of paralexification in 5. can be viewed as paralabelling in 1.b., the first step in relabelling. Both representations describe a process which, in its initial stage, consists in creating a second phonological representation for a given lexical entry. Paralexification can thus be equated with paralabelling.

\subsubsection{Calquing as relabelling}

In his work on Solomon Island Pidgin, Keesing $(1988: 1,2)$ writes:

Sitting on a Solomon Island mountain in 1977, [...] I was led to think more seriously than I ever had about the history and structure of Solomon Island Pidgin. I had earlier been struck, when I had learned Solomon Pidgin in the 1960s through the medium of Kwaio, an indigenous

\footnotetext{
${ }^{4}$ This is a welcome result, because some people sometimes wrongly interpret relexification as yielding a language that has the lexicon of one language and the syntax of another. This view is hard to take seriously given that, in current models of grammar, syntax is the projection of the lexicon.
} 
language I already spoke fluently, that this learning task mainly required learning Pidgin equivalents of Kwaio morphemes. The syntax of Solomon Pidgin was essentially the same as the syntax of Kwaio, although somewhat simpler and lacking some of the surface marking; in most constructions, there was a virtual morpheme-by-morpheme correspondence between Kwaio and Pidgin. [...] Although most of the Pidgin lexical forms were ultimately derived from English, I found this largely irrelevant to my language-learning task. The semantic categories they labelled corresponded to Kwaio ones, not English ones; grammatical morphemes corresponded to Kwaio ones, not English ones. Thus semantically Pidgin dae corresponded directly to Kwaio mae 'be dead, die, be comatose, be extinguished,' not to English 'die'. Pidgin baebae corresponded to the Kwaio marker of future/ non accomplished mode, ta-, not to English 'by and by'.

Keesing identifies the data he describes as resulting from the process of calquing. In this view, the creators of the Pidgin calqued the properties of their native lexicons (e.g., Kwaio) onto English forms. The term calquing is used by Keesing to refer to the process that I refer to as relabelling. Furthermore, the results of calquing, as described above, present the division of properties that is expected of lexical entries produced by relabelling (see 1.). The conclusion I draw from this state of affairs is that cases of calquing, such as those described by Keesing, are in fact cases of relabelling.

\subsubsection{Transfer and relabelling}

The notion of transfer (which goes back to Weinreich 1953:1) refers to the use of features of their first language by speakers who are speaking a second language. For Andersen (1983:7), this process may also manifest itself in second language acquisition: "Transfer from a learner's previously acquired language (...) is assumed to interact with the normal acquisitional process by causing the learner to perceive input in terms of certain aspects of the structure of the previously acquired language." In Siegel's (1995, to appear: 11) view, transfer manifests itself in the formation of creole languages: "Here I am defining substrate influence as the evidence of transfer (or interference) at an earlier stage of development. Transfer refers to speakers unconsciously carrying over features from one language (usually their first) when speaking (or trying to speak) another language."

Some cases of transfer may involve only a subset of features. Others, however, may involve the entire set of features of a given lexical item. Such cases are in fact cases of relabelling. For example, in the Full Transfer/Full Access model of second language acquisition developed by Schwartz \& Sprouse (1996:41) and related work, "the entirety of the $L_{1}$ grammar (excluding the phonetic matrices of lexical/morphological items) is the $L_{2}$ initial state (hence the term "Full Transfer")". Sprouse (2006:170) further states that "Full Transfer can be restated in terms of Relexification' and that 'Relexification is at the core of the second language instinct, accounting both for the $L_{2}$ initial state and for the frequent failure of failure-driven revision to effect convergence on the target language." As is extensively discussed by Lardière (2006), however, with sustained exposure to $\mathrm{L}_{2}$, $\mathrm{L}_{2}$ learners do go beyond relexification and actually acquire features of $\mathrm{L}_{2}$. And the claim that there is a relationship between the notion of transfer as it applies in creole genesis and the process of relexification goes back to Naro (1978:337): "A transfer process of this general sort, termed RELEXIFICATION, ...." In some cases, then, transfer corresponds to relexification, hence to relabelling. 


\subsubsection{Misascription and relabelling}

Another term used in the sense of relabelling is misascription. This word is used by Allsopp (1980:95) to refer to cases of full transfer of substratum features to an incipient creole's lexical entry. 'By this term I mean not only the semantic shifting, but the ascribing of the wrong sense or the wrong usage or the wrong grammatical function to a word or phrase of the target language.' What Allsopp means by 'wrong' corresponds to a speaker's native language features.

\subsubsection{Reinterpretation, restructuring and relabelling}

The process of restructuring, as described by some authors, produces results that are comparable to those produced by relabelling. For example, consider Migge's (2003:12) general statement concerning the processes involved in the creation of English Maroon Creoles (EMC):

In relation to the processes and mechanisms of contact involved in creole formation, sociohistorical research suggests that the agents of creole formation acquired structures from the dominant European varieties and structurally reinterpreted them based on the patterns from their native languages. ${ }^{5}$ The degree of reinterpretation was constrained by the nature of the contact setting(s). Settings in which the majority of the agents of creole formation had little access to the European varieties (cf. Suriname creole) triggered a relatively great amount of reinterpretation while settings involving a relatively great amount of knowledge of the European varieties gave rise to a relatively small degree of restructuring.

Examples of the output of restructuring provided by Migge (2003:63) are reproduced in 6.:

\begin{tabular}{|c|c|c|c|}
\hline \multirow[t]{2}{*}{6.} & EMC & GBE & ENGLISH \\
\hline & $m o f u$ & $n u$ & mouth \\
\hline Meaning & $\begin{array}{l}\text { animate mouth, opening, } \\
\text { edge beginning/end, } \\
\text { message, word }\end{array}$ & $\begin{array}{l}\text { animate mouth, opening, } \\
\text { edge, beginning/end }\end{array}$ & $\begin{array}{l}\text { animate mouth, opening } \\
\text { of a river }\end{array}$ \\
\hline \multirow[t]{2}{*}{ Category } & $\mathrm{N}$ & $\mathrm{N}$ & $\mathrm{N}$ \\
\hline & ondo(o) & $\begin{array}{l}\operatorname{gom\varepsilon }(\mathrm{A}, \mathrm{G}), \text { gule }(\mathrm{M}), \\
\operatorname{goma}(\mathrm{W}), \text { gun }(\mathrm{X})\end{array}$ & under \\
\hline Meaning & $\begin{array}{l}\text { lower side, under or } \\
\text { below some location }\end{array}$ & $\begin{array}{l}\text { lower side, under or } \\
\text { below some location }\end{array}$ & $\begin{array}{l}\text { under or below some } \\
\text { location, less than, in } \\
\text { some condition }\end{array}$ \\
\hline \multirow[t]{2}{*}{ Category } & $\mathrm{N}$ & $\mathrm{N}$ & $\mathrm{P}$ \\
\hline & $G i$ & $\mathrm{Na}$ & give \\
\hline Meaning & $\begin{array}{l}\text { give, present; marks } \\
\text { recipient, benefactor, } \\
\text { experiencer, etc., comp. }\end{array}$ & $\begin{array}{l}\text { give, present; marks } \\
\text { recipient, benefactor, } \\
\text { experiencer, etc., comp. }\end{array}$ & give, present \\
\hline Category & $\mathrm{V}, \mathrm{P}$, comp. & $\mathrm{V}, \mathrm{P}$, comp. & V \\
\hline
\end{tabular}

(from Migge 2003:63)

\footnotetext{
5 In my view, one cannot both 'acquire' and 'reinterpret' structures. By definition, these two options must be mutually exclusive.
} 
Note that the word $n u$ in the first example in 6. is also used in the expression 'say a word' in Fongbe: $k \varepsilon$ nu dokpó ('open mouth one') (Rassinoux 2000). The examples in 6. show that the results of the process referred to by Migge as restructuring correspond to those of the process I refer to as relabelling.

\subsubsection{Reanalysis and relabelling}

Reanalysis is yet another term sometimes used with the meaning of relabelling. Siegel (2000:1) cites a standard definition of reanalysis: "The historical process by which a well-formed surface string comes to be interpreted as having a different structure from formerly" (Trask 1993:228). Siegel goes on: "In language learning and in language contact situations, structures from the target language (usually the superstrate language) may be reinterpreted according to the syntactic or semantic properties of the learner's native language (the substrate language). The process of reinterpretation is basically the same, although in the case of language contact, it is influenced by another language and may lead to the creation of a new variety rather than to internal change in the existing variety." (p. 2). Siegel further writes: "In the context of language contact, this process is referred to as "relexification" by some researchers (Lefebvre 1998; Lumsden 1999) [...]" (p. 2), hence relabelling. An example of reanalysis used in the sense of relabelling is provided by Koch (2000), who seeks to explain the presence of the transitivity marker -im on Australian Pidgin verbs, modelled on the substrate languages of this pidgin. Koch establishes that the form of the transitivity marker comes from the reduced forms of English him and them, phonologically cliticised onto the verb that precedes them. According to his analysis, these forms have been reanalysed as part of the verb: "This reanalysis of the object enclitics as part of the verb would have been facilitated by certain expectations based on the phonotactics of their first language ALs" (Koch 2000:18). Koch's use of the term reanalysis here corresponds to my definition of relabelling. Other authors use the term reanalysis in the same way as Koch does (e.g., Bruyn 2003; Detges 2003; Kriegel 2003 and several chapters therein; as well as several chapters in Siegel 2000).

\subsubsection{Summary}

In the literature, we find several terms that are used to refer either to the same process as that referred to by the term relabelling, or to the same end result as that produced by relabelling. The terms that have been discussed are the following: relexification, paralexification, calquing (in some cases), transfer (in some cases), misascription, reinterpretation, restructuring, and reanalysis. Other terms such as language intertwining, which corresponds to relexification in Bakker's (1994) framework; imposition (Van Coetsem 2000), as discussed in Winford (2008); and possibly metatypy, as used by Ross (2007), could possibly be added to the list. ${ }^{6}$ When all these cases are identified as instances of relabelling, the process is seen to be more widespread in terms of tokens of use than it appears at first glance. As will be seen below, relabelling is also important for another reason: it is called upon in a wide variety of language contact contexts.

\footnotetext{
${ }^{6}$ These terms may involve conceptual differences. For example, from a conceptual point of view, relabelling, like relexification and paralexification, consists in associating a label from $\mathrm{L}_{2}$ with features defining a $\mathrm{L}_{1}$ lexical entry. In contrast, transfer, reanalysis or restructuring, as discussed above, consist in associating the features of a $\mathrm{L}_{1}$ lexical entry with a label in $\mathrm{L}_{2}$. In spite of the conceptual difference between the processes discussed in this section, all yield the same result, that is, lexical entries that inherit their semantic and syntactic properties from $\mathrm{L}_{1}$ and their labels from $\mathrm{L}_{2}$. This justifies considering these processes as one and the same. I leave the discussion of the conceptual differences in the directionality of the processes for future research.
} 


\subsection{Relabelling across language contact situations}

As we saw in the preceding section, relabelling is claimed to be extensively used during the first stage of acquisition of a second language (Sprouse 2006). It is also used by bilingual speakers. I am referring here to cases of interference that involve full transfer of features. The literature abounds in examples of this type. I will provide only one, taken from Lafage (1985), who shows that some Gbe-French bilingual speakers tend to use the determiner system of Gbe when speaking French. This is illustrated in 7. In a., we see that the nominal determiner follows the noun auto as in Gbe. In b., we see that the possessor is realised as a personal pronominal form following the noun, again as in Gbe. ${ }^{7}$ In c., the form là is identified by Lafage as an article de phrase 'clausal determiner', which corresponds to the Gbe clausal determiner.

7. a. N'y a qu'à pousser auto-là.

'All you need to do is to push the car.'

b. Père-lui

father he

'his father'

$\begin{array}{lllll}\text { c. Son argent } & n^{\prime} a & \text { pas } & \text { suffi } & \text { là } \\ \text { his money } & \text { BE.AUX } & \text { NEG } & \text { be.enough } & \text { Det }\end{array}$

'His money was not enough.'
$\mathrm{L}_{2}$ FRENCH, $\mathrm{L}_{1}$ EWE

(Lafage 1985:409)

$\mathrm{L}_{2}$ FRENCH, $\mathrm{L}_{1}$ EWE

(Lafage 1985:417)

(Lafage 1985:407)

As will be seen in the next section, relabelling is also extensively involved in the creation of mixed languages such as Media Lengua, Michif, Ma'a, Romani, etc. These languages are created by bilingual speakers in bi-ethnic communities in order to mark an ethnic group identity and set this group apart from the neighbouring ones (see the papers in Bakker \& Mous 1994b). According to the discussion above, relabelling is also a major process in the formation of creole languages (e.g., Bruyn 2003; Koch 2000; Lefebvre 1998 and the references therein; Migge 2003; etc.). Creole languages are created in contexts where several substrate languages and a superstrate language come into contact and where a lingua franca is needed in order to permit speakers who do not have a common language to communicate with one another. In these contexts, speakers of the substrate languages have limited access to the superstrate language, a situation that is very favourable to relabelling. The relabelling of several substratum lexicon on the basis of one (or two) superstrate language(s) provides the speakers of an early creole community with a common vocabulary (see Lefebvre \& Lumsden 1994). Finally, according to Hill \& Hill (1977), situations of language death also involve relabelling. They show that the lexicon of Tlaxcalan Nahuatl, an indigenous language of Mexico, is being relexified - thus relabelled-by Spanish words, which is contributing to the death of the language.

All of the above language contact situations involve relabelling. The language varieties that have resulted from this process, however, do not all have the same surface characteristics. As we will see in the next section, this is primarily due to the variable extent of relabelling across lexicons.

\section{The extent of relabelling across lexicons}

This section considers several case studies illustrating the fact that the variable extent of relabelling across lexicons may yield different language varieties. In turn, the extent of relabelling across lexicons is shown to correlate with a number of factors that define the situations in which the process is called upon. These factors include the number of languages involved, the amount of access to the 'lexifier'/ 'target'/ $\mathrm{L}_{2}$ language, whether code switching is involved, and whether language shift is involved.

\footnotetext{
${ }^{7}$ In Gbe, the pronominal form is followed by a genitive case marker. Such a case marker is not overtly manifested in the French of Ewe speakers.
} 


\subsection{Relabelling of major category lexical items: Media Lengua}

Media Lengua (ML) (Ecuador) is a mixed language created by bilingual Quechua-Spanish speakers (see Muysken 1981, 1988). The phonological representations of its lexicon are derived from two sources. While the labels of major category lexical entries (i.e., nouns, verbs, adjectives, postpositions) are almost entirely derived from Spanish, the labels of affixes and functional categories are from Quechua. The examples in 8. and 9. illustrate this division. (In the Media Lengua examples below, the Spanish forms are in regular characters and the Quechua ones in italics.)

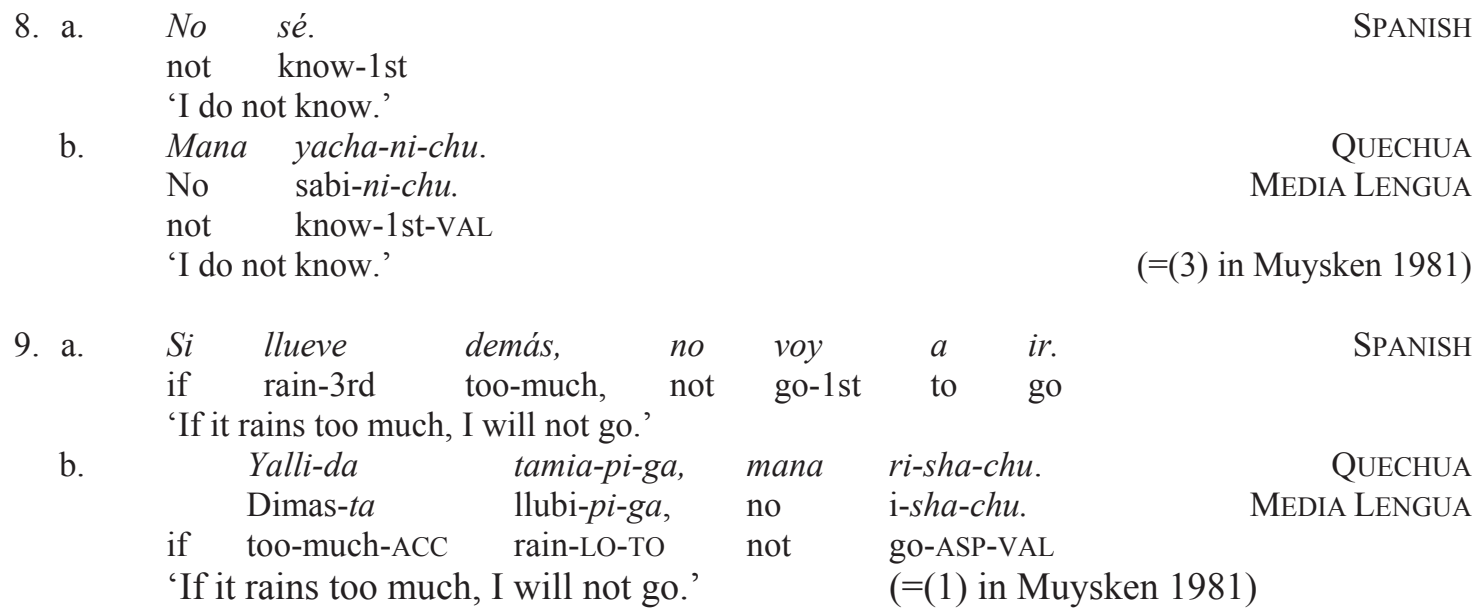

Although the lexical categories of ML derive their labels from Spanish, their semantic content is derived from Quechua. In 10. we see that the meanings associated with the ML form sinta-ri$(<$ Sp. sentarse) correspond to those associated with the Quechua tiya-ri-. In contrast, there is only one meaning associated with the Spanish verb sentarse: 'sit down'. The other meanings that are associated with sinta-ri- and tiya-ri- in ML and Quechua, respectively, correspond to different verbs in Spanish: estar sentado 'sit', vivir 'live', estar 'locative be' and hay 'there is' (Muysken 1981:56).

$\begin{array}{lll}\text { 10. } \mathrm{ML} & \text { SPANISH } & \text { QUECHUA } \\ \text { sinta-ri- } & \text { sentarse 'sit down' } & \text { tiya-ri- } \\ \text { 'sit' } & \text { estar sentado } & \text { 'sit' } \\ \text { 'live' } & \text { vivir } & \text { 'live' } \\ \text { 'locative be' } & \text { estar } & \text { 'locative be' } \\ \text { 'there is' } & \text { hay } & \text { 'there is' }\end{array}$

Lexical entries of this type have been created through relexification (Muysken 1981), that is, through relabelling.

In short, ML represents a case where only major category lexical items have been relabelled.

\subsection{Relabelling of major category lexical items and of some affixes: Inner Mbugu or Ma'a}

Inner Mbugu (IM) or Ma'a (Tanzania) is a mixed language created by Normal Mbugu (NM) (Bantu) speakers (see Mous 1994, 1995, 2001). Mous (2001) emphasises that corresponding lexical entries in IM and NM are complete synonyms, even though their phonological representations are different. A sentence containing the verb 'to break' exemplifies this fact.

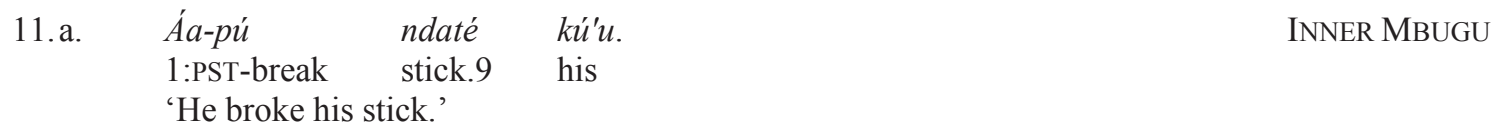


$\begin{array}{lll}\text { b. Áa-baha } & \text { ndatá } & \text { y-akwé. } \\ \text { 1:PST-break } & \text { stick.9 } & \text { 9-his }\end{array}$

NORMAL MBUGU

'He broke his stick.'

$(=(5 a)$ in Mous 2001)

Another set of examples illustrating semantic parallels between IM and NM is provided in 12 ., showing that, in both languages, parallel lexical items share metaphorical uses.

12.

$\begin{array}{ll}\text { IM } & \text { NM } \\ \text { mxatú } & \text { mti } \\ \text { hlúku } & \text { gwisha } \\ \text { hi } & \text { chuma } \\ \text { gewa } & \text { jughulwa }\end{array}$

'tree, afterbirth'

'to drop, give birth'

'to sew, mould'

'to be opened, to be allowed to get married'

$(=(6)$ in Mous 2001)

An extensive discussion of the various sources of the phonological representations of IM lexical entries may be found in Mous (2001). Suffice it to say here that these phonological representations come from a variety of neighbouring languages, including Cushitic ones, and from modifications of the corresponding forms in NM. In this respect, IM or Ma'a differs from the other reported cases of mixed languages (e.g., Media Lengua) in which the phonological representations of the relabelled lexical entries are generally derived from only one language (e.g., Spanish in the case of ML).

Both IM and NM share the same grammar, which is basically Pare. They share the same complex verbal inflectional system, the same richness in 'tense' (over 40 tenses have been identified so far). 'The two varieties share all of these tenses with exactly the same morphological form, including tone patterns' (Mous 2001:293). Both languages share the same complex system of subject and object concords, realised by the same morphological forms. They have the same verbal suffixes and the same tense, mood and aspect prefixes and suffixes (see Mous 1994, 2001). Based on the above description, IM or Ma'a can be characterised as having major category lexical items with the properties of those of NM but labels derived from surrounding languages, and functional category lexical items from NM. IM or Ma'a would appear to be identical in nature to Media Lengua were it not for the fact that noun class morphemes have also been relabelled. Examples of noun class morphemes in IM and NM are provided in 13. along with the hypothesised source of the IM form.

\begin{tabular}{|c|c|c|c|c|c|}
\hline NM / Pare & & Subj. & Obj. & IM & Source of IM \\
\hline$m-n h t u$ & 'person' & $\dot{e} / \dot{a}$ & $m u ̀ ~$ & $m$-hé & Iraqw (SC): hee \\
\hline va-nhtu & 'people' & vé/vá & $v a ́$ & $v a-h e ́$ & Iraqw (SC): hee \\
\hline m-kóno & 'arm' & $\dot{U}$ & $\dot{u}$ & m-harégha & Oromo (EC): harka \\
\hline mi-kóno & 'arms' & $\dot{I}$ & $i$ & mi-harégha & Oromo (EC): harka \\
\hline vu-shó & 'face' & $V u ́$ & $v u ́$ & vu-basá & Origin unclear \\
\hline ma-shó & 'faces' & $\dot{e} / \dot{a}$ & $a ́$ & $m a-b a s a ́$ & $\begin{array}{l}\text { Origin unclear } \\
(=(14) \text { in Mous 1994:187) }\end{array}$ \\
\hline
\end{tabular}

In short, IM or Ma'a represents a case where, in addition to major category lexical items, some affixes have been relabelled.

\subsection{Relabelling of some major category lexical items with code switching: Michif}

Michif is a Cree-French mixed language developed by the Métis buffalo hunters of Canada and the northern United States (Bakker 1989, 1992, 1994; Papen 1988). The phonological representations of its lexicon are derived from two sources: French and Cree. 
As in Media Lengua, where all affixes are from Quechua, in Michif all affixes are from Cree. These affixes appear on both nouns and verbs regardless of whether they are of French or Cree origin. For example, in 14. the obviative affix occurs on the object noun. (In the Michif examples below, words of Cree origin are in italics; words of French origin are in regular characters.)

$\begin{array}{llllll}\text { 14. La jument } & \text { l' étalon } & - \text { wa otin } & - & \hat{e} w . \\ \text { the mare the } & \text { stallion } & - & \text { OBV take } & - & (\mathrm{s}) \mathrm{he} / \mathrm{him} / \mathrm{her}\end{array}$ 'The mare takes the stallion.' $\quad(=(3)$ in Bakker 1994:21)

In 15., the Cree affix -ipan 'deceased' is suffixed to a noun of French origin.

$\begin{array}{lll}\text { 15. mũ } \quad \text { vjø }- & \text { ipan } & \text { MICHIF } \\ \text { my husband } & \text { deceased } & (=(49) \text { in Bakker 1992:169) } \\ \text { 'my deceased husband' } & & \end{array}$

Similarly, in 16. the Cree plural suffix appears on a noun of French origin.

$\begin{array}{lllllllll}\text { 16. John tahkuht }- & \text { am } & \text { li: } & \text { fiy } & \text { anIhl } & \text { si: } & \text { zarcj } & - \text { Iwa: } w . & \text { MICHIF } \\ \text { John bite } & 3->4 & \text { AP } & \text { girl } & \text { DEM-OBV } & \text { 3.POSS.PL } & \text { ear } \begin{array}{c}-3 . P L \\ (=(56) \text { in Bakker 1992:171) }\end{array}\end{array}$

Cree affixes also occur on verbs which are of French origin as in 17.
17. $g i: \quad-1 \imath-$ ga:ž :
1.PST the bet
$-\quad n$
INFL.1
syr $\quad 1 l \quad$ brõ .
on the brown
MICHIF
'I bet on the brown one.'
(=(74) in Bakker 1992:174)

The above data illustrate the kind of mix found in Michif. As Bakker (1994:167) observes: "Michif structure is the result of the combination of Cree grammar with French lexicon. [...] The grammatical bound elements are Cree and the lexical-free elements are French." As he points out, however, while $90 \%$ of nouns have a French form, a mere handful of verbs have a phonological representation derived from French and the great majority have come from Cree. According to Bakker, the verb generally has a Cree form because it consists of grammatical bound elements. ${ }^{8}$

Michif nouns appear to have been derived by relabelling. While their semantic and syntactic properties are derived from Cree, their phonological representations are derived from French. For example, Michif nouns are identified for the feature [ $\alpha$ animate], as Cree nouns, rather than for the feature [ $\alpha$ feminine], like French nouns. This can be seen in the fact that Michif demonstratives, which are of Cree origin, agree in number and animacy with the nouns they modify. The Michif agreement facts are illustrated in 18 .

\footnotetext{
${ }^{8}$ Bakker (1994: 21) attributes this fact to the polysynthetic nature of Cree: For the mixed language of the Métis, one would expect a Cree grammatical system with French lexicon. But the problem is that here it is impossible to combine the two in the same way as in the other cases, due to its polysynthetic structure and often blurred morpheme boundaries in the verb. There is a continuum between stem-formational, derivational and inflectional morphemes in the verb, which makes it impossible to separate the stems from the affixes. French verb stems cannot be combined with Cree verbal morphology without destroying the whole organisation of the Cree structure (only in some marginal cases which look like loanwords this is apparently possible, as discussed above). For that reason, Cree verbs belong as a whole to the grammatical system and therefore have to remain Cree in a combination with other languages.
} 


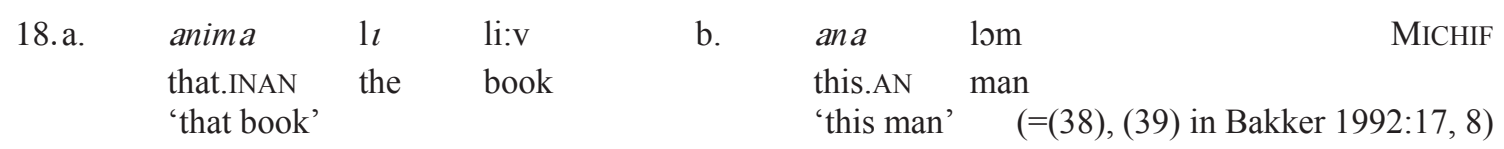

A second example showing that the Michif lexical entries must have been created through relabelling resides in the semantic properties of the locative preposition da/dã meaning 'in, on, at'. This preposition derives its phonological representation from the French preposition dans 'in'. As noted by Bakker (1992:171), however, the range of meanings covered by the Michif preposition is much wider than that covered by its French source, but parallels that of the corresponding Cree lexical entry. Cree has a locative postposition -ihk (with an allomorph -ohk) meaning 'in, on, at'. These facts are illustrated in 19. and 20.

\begin{tabular}{|c|c|c|}
\hline \multirow[t]{2}{*}{ 19. a. } & $\begin{array}{llll}\text { ãnarjer } & \mathrm{dã} & 1 \iota & \check{\mathrm{s}} \text { a:r } \\
\text { in-back } & \text { LOC } & \text { the } & \text { car }\end{array}$ & MichIF \\
\hline & 'behind the car' & $(=(57)$ in Bakker 1992:171) \\
\hline \multirow[t]{3}{*}{ b. } & otãpãnask-ohk & CREE \\
\hline & behind car LOC & \\
\hline & 'behind the car' & $\left(=\left(59^{\prime}\right)\right.$ in Bakker 1992:171) \\
\hline \multirow[t]{2}{*}{ 20.a. } & dã $\quad 1 l \quad$ fr $\iota \mathrm{dž}$ & MICHIF \\
\hline & $\begin{array}{l}\text { LOC the fridge } \\
\text { 'out of the fridge' }\end{array}$ & $(=(58)$ in Bakker 1992:171) \\
\hline \multirow[t]{3}{*}{ b. } & tahkascikan-ihk & CREE \\
\hline & fridge LOC & \\
\hline & 'out of the fridge' & $\left(=\left(58^{\prime}\right)\right.$ in Bakker 1992:171) \\
\hline
\end{tabular}

Many more examples of the same type are provided in Bakker $(1989,1994)$.

So, like Media Lengua, Michif is a mixed language produced by relabelling. The type of mix we find in Michif, however, is different from the mix in Media Lengua. While almost all major category lexical items in Media Lengua derive their phonological representations from Spanish, in Michif only a subset of these, mainly nouns, have been relabelled. Furthermore, words associated with the nominal structure tend to have labels derived from French, whereas words associated with the verbal structure tend to have labels derived from Cree. Although the forms of personal and demonstrative pronouns come from Cree, the forms of possessive pronouns are from French. Numerals and adjectives always come from French. As for adpositions, the forms of prepositions in Michif tend to be derived from French and those of postpositions from Cree. Adverbial particles, negative elements and conjunctions appear to be drawn from both source languages. Articles are from French and verbal morphology from Cree. In light of this description, it appears that Frenchderived lexical elements are predominant in noun phrases, while Cree lexical elements predominate in verb phrases. How did this situation arise? It appears that, in this case, in addition to relabelling, code switching between NPs and VPs has also played a role in the makeup of the language (e.g., Papen 1988; Muysken 2007, and the references therein). This led to data such as those in 14. to 17. where the nominal structures, including the article, are from French, and the verbal structures are from Cree.

To sum up, Michif represents a case where relabelling has applied to lexical categories, excluding verbs, and where the French nominal structures and Cree verbal structures reflect an earlier stage of code switching between the two languages by bilingual speakers. 


\subsection{Relabelling and language shift: Angloromani}

Angloromani is a mixed language created by bilingual Romani-English speakers shifting to English (Boretsky \& Igla 1994). The phonological representations of its lexicon are derived from two sources. While the labels of major category lexical entries are from Romani, the labels of functional categories are from English. Boretsky and Igla demonstrate that almost all bound grammatical morphemes of English occur in Angloromani. This is exemplified in 21. from Leland (1874), cited in Boretsky \& Igla (1994:47).

$\begin{array}{ll}\text { 21. Plural -s: } & \text { chal-s } \\ \text { Genitive - 's: } & \text { mo kako's chavo } \\ \text { 3rd person -s: } & \text { pen-s } \\ \text { Past -ed: } & \text { chin-ed } \\ \text { Progressive -ing: } & \text { haw-in } \\ \text { Comparative -er: } & \text { kushti-er } \\ \text { Superlative -est } & \text { kushti-est } \\ \text { etc. } & \end{array}$

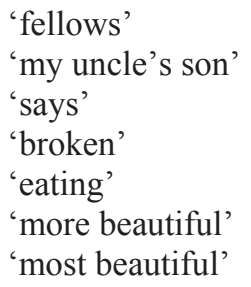

(Boretsky \& Igla 1994:47)

Boretsky \& Igla (1994:60) remark that there are two ways of looking at the genesis of Angloromani. "One might speak of Romani having replaced its grammar-regrammaticalisation, or of another language having replaced its lexicon—relexification." They argue at length against the former view, and in favour of the latter. "Our claim is that the Romani mixed dialects came into being by the relexification of the contact language, and, furthermore, that this was an intentional process that could only occur at a given stage between bilingualism and language shift, [...] when the speakers as an entire group are no longer fully bilingual, but have not accomplished language shift either" (p. 60). According to Boretsky \& Igla, the speakers who played the most active role in creating the mixed language were those who no longer had Romani as their mother tongue, but English. They relabelled the major category lexical items of English on the basis of Romani words to which they still had access.

Briefly Angloromani represents a case where the major category lexical entries of the contact language, in this case English (instead of those of the community's first language) have been relabelled on the basis of that first language.

\subsection{Relabelling of whole lexicons: radical creoles and languages that were created in similar situations}

Radical creoles are those which are farthest from their superstrate language (e.g., Haitian, Saramaccan). The phonological representations of their lexical entries are derived from one (e.g., Haitian) or possibly two (e.g., Saramaccan) superstrate languages, and the bulk of the semantic and syntactic properties are derived from the substrate languages (West African languages in both these cases). The fact that hardly any forms have been retained from the substrate languages ${ }^{9}$ suggests that, in creolisation, the bulk of substrate lexical entries are relabelled. This differs from mixed languages in which the original lexicons are only partially relabelled. Why do we see this difference between creoles and mixed languages?

Situations where creoles emerge differ from those in which mixed languages emerge. First, while the creation of mixed languages generally involves only two languages (e.g., Media Lengua, Michif, Angloromani), the creation of creole languages generally involves several: generally one superstrate language and several substrate languages (e.g., Haitian). Second, while mixed languages are created to identify in-group speakers and set them apart from neighbouring groups, creole languages are created to serve as a lingua franca allowing speakers of different native languages to

\footnotetext{
${ }^{9}$ For a discussion of this fact, see Lefebvre (1998, 2002).
} 
communicate. Third, while the creators of mixed languages speak both languages involved, the creators of creole languages generally have little access to the superstrate language. These differences have a major impact. Since mixed languages involve only two languages, and since the creators of mixed languages are bilingual, the extent of relabelling across the original lexicons may involve only a portion of the lexicon. Relabelling only has to be extensive enough to make the new language incomprehensible to the outsiders. However, since creole languages involve several languages, the creators of a creole have limited access to the superstrate language, the purpose of creating a creole is to provide a multilingual community with a lingua franca, the extent of relabelling of the original lexicons has to involve the entire lexicons, including affixes and functional categories. Of course, the development of creoles does involve other processes than relabelling (e.g., grammaticalisation, reanalysis, lexical diffusion, levelling, etc.), which are not necessarily involved in the development of mixed languages (see Lefebvre 1998 and the references therein, 2006). ${ }^{10}$

At first glance, the fact that substrate forms are essentially absent from a given creole hides or downplays the contribution of substrate languages. Recent detailed three-way comparisons between a creole's lexicon and the lexicons of its contributing languages (substrate and superstrate) have shown, however, that although the labels of the creole's lexical entries come from the superstrate, the bulk of their semantic and syntactic properties come from the substrate languages (e.g., Koopman 1986; Lefebvre 1998; Migge 2003; etc.). Furthermore, patterns of variation between the substrate languages have been shown to be reproduced in a creole through relabelling. For example, Haitian Creole exhibits patterns of variation in its determiner system, its TMA system, the distribution of the clausal determiner, etc. In Lefebvre (1998), it is demonstrated that these patterns of variation reproduce those that are manifested in Haitian's substrate languages. Similar data are also documented for other creoles such as Solomon Island Pidgin, to which I now turn.

Solomon Island Pidgin is a creole whose substrate languages are both Austronesian and nonAustronesian Papuan languages, and whose lexifier language is English. While Keesing (1988) documents the fact that the variety of Solomon Island Pidgin he studied reproduces the properties of Austronesian languages such as Kwaio (see section 1), Terrill \& Dunn (2006) show that the variety of Solomon Island Pidgin they studied reproduces the properties of non-Austronesian Papuan languages. Furthermore, the latter study involved speakers of two of Solomon Island Pidgin's nonAustronesian Papuan substrate languages: Lavukaleve and Touo, which are not known to be related to each other. The overall conclusion of Terrill \& Dunn's study is that the variety of Solomon Island Pidgin spoken by the Lavukaleve reproduces the semantic properties of Lavukaleve, whereas the variety spoken by the Touo reproduces the semantic properties of Touo. Similar data are also reported for Singapore English.

Although Singapore English is not referred to as a creole in the literature, the conditions under which it has developed are very similar to those in which radical creoles develop. Indeed, the creation of Singapore English involved several Chinese languages/dialects, Malay and Tamil, as its substrate languages, and English as its superstrate language. Bao \& Wee (2005) show that 'the aspectual system of Singapore English is essentially the Chinese one filtered through the morphosyntax of English. Substrate influence is systemic, and the competing grammatical subsystems do not mix' (Bao \& Wee 2005:237). They point out that the substrate transfer is not complete, however, as the stative imperfective and the tentative aspects have not been reproduced in Singapore English (p. 250). ${ }^{11}$ Bao \& Lye (2005) further show that Singapore English, like Chinese

\footnotetext{
${ }^{10}$ Creoles that are less 'radical', that is, those that are closer to their superstrate language represent cases in which there has been more exposure to the superstrate language, and thus less relabelling (see Lefebvre 1998, 2006).

${ }^{11}$ In my view, this might be due to the absence of available forms in the lexifier language.
} 
(the main substrate language) is topic-prominent and that the structure of the conditional construction 'is a direct consequence of this typological status' (p. 267). These points suggest that Singapore English was formed through relabelling. A strong argument in favour of this view is supported by the fact that, as Bao \& Wee (1999) document, there are three passive constructions in Singapore English: one that corresponds to English (the by-phrase construction), one that corresponds to Malay (the kena construction), and one that corresponds to Chinese (the give construction). The first one corresponds to the grammar of speakers who have mastered English as a second language. The other two correspond to the versions of the passive produced by speakers of the substrate languages, Malay and Chinese, respectively, who have not mastered English, and who relabelled the lexical items involved in their own passive constructions with English words.

In brief, creole languages, and languages that were created in similar situations, represent cases where the whole lexicons of substrate languages have been relabelled on the basis of the superstrate language(s).

\subsection{Summary}

The various case studies summarised in this section show that the extent of relabelling across lexicons varies between situations. This variation correlates with a number of factors, including the number of languages involved (two in the case of mixed languages, versus several in the case of creole languages), the amount of access to the 'lexifier'/'target'/ $L_{2}$ language (e.g., little in the case of radical creoles, more in the case of not so radical creoles), whether code switching is involved (e.g., Michif), and whether language shift is involved (e.g., Romani). Other variables may also be involved. Those I discussed in this section appear to be the prominent ones on the basis of the available documentation.

The cases of relabelling that have been discussed so far involve major category lexical items and some affixes (cf. IM or Ma'a). The sole agglutinative language discussed in this section was Cree, the substratum language of Michif. We saw that, in the formation of Michif, the agglutinative morphology remained Cree. Does this entail that the semantics encoded in agglutinative morphology cannot be reproduced by relabelling? In the following section, I show that the answer to this question must be negative.

\section{Extensive relabelling involving agglutinative languages: Kriol}

Kriol is the creole language that emerged from the contact between some hundred Aboriginal languages and English, in Australia (Roper River) around 1908 (Munro 2000). Kriol was created in order to provide the Aboriginal people, who found themselves in contact, with a lingua franca. It is therefore like other creole languages in having several substrate languages and one superstrate language. However, Kriol shares one important feature with Michif, a mixed language, in that, like Cree (the Michif substrate language), all of its substrate languages are agglutinative (Munro 2000). We saw that in the formation of Michif, nominal lexical items were relabelled (though not verbs), but affixes all remained Cree. As Bakker (1994) points out, the Cree verb and its affixes are agglutinated in such a way that it is difficult to separate them, and thus, I assume, to relabel them. On the other hand, we saw that in Inner Mbugu or Ma'a some affixes have been relabelled (see 13.). Thus, it is actually possible to relabel affixes (see also Lefebvre 2003 based on Haitian). Furthermore, since Kriol is a creole with close to a hundred substrate languages, the substrate lexicons had to be relabelled in their entirety for a lingua franca to be created (see section 2). On the other hand, according to Hesseling (1933:xvi), Schuchardt (1979) and others, creoles tend to be isolating languages even when their substrate languages are agglutinative. For example, Mufwene (1986) claims that Kituba, a creole that has emerged almost exclusively from contact among agglutinative Bantu languages, is an isolating language (Mufwene 1990:12). Mufwene did not 
provide any data supporting his claim, but other authors working on creoles that have arisen from agglutinative substrate languages, such as Kriol, have documented the same claim.

What do we find in Kriol? On the basis of the available literature, we can say that we find evidence of two options: some affixes have been relabelled as affixes, while others have been relabelled as free morphemes. These two options will be illustrated in turn.

Examples of affixes that have been relabelled as affixes are discussed in Koch (2000). Aboriginal languages have a transitivity marker on the verb. This morpheme has been relabelled in Kriol, on the basis of English him/it following the English verb. Similarly, the substrate nominal modifier has been relabelled on the basis of English fellow, yielding pela in Kriol. This morpheme is found on adjectives, demonstratives and pronouns (see 25. below).

As Munro (2004) shows in great detail, the bulk of the agglutinated morphology of the substrate languages of Kriol has been relabelled as free morphemes in the creole. For example, in Aboriginal languages, tense, mood and aspect are realised as postverbal markers (see 22.). In Kriol, tense, mood and aspect are realised as preverbal periphrastic markers (see 23.). According to Munro, the free forms in Kriol have the same properties as the bound ones in the substrate languages.

22. Gu-jandah Ø-marninyh-mi-ti-tji-ny. NC-stick 3sg-make- AUX -RCP-PP

'He made himself into a stick.'

NGALAKGAN

(Merlan 1983:104-105)

$\begin{array}{lllllll}\text { 23. Main mamai } & \text { bin } & \text { oldei } & \text { gemp } & \text { langa } & \text { gemp. } \\ \text { POSS } & \text { mother } & \text { PST } & \text { CONT } & \text { live/stay } & \text { G/L } & \text { camp }\end{array}$ 'My mum stayed (slept) at camp.'
KRIOL

Sharpe (1972:9) notes that "In Alawa [a substrate language of Kriol] tense-aspect-mood... are indicated by suffixation of auxiliary stems...; in PE [pidgin English, or Kriol] they are indicated by preposed words. However, the contrasts distinguished are found to be in nearly all respects identical. In surface structure the languages are very different; in deep structure and semantically they are almost identical."

Yet another example involves negative morphology. In Aboriginal languages, negative morphology is realised by different morphemes depending on whether the mood is realis or irrealis. This distinction has been carried over in Kriol which has neba and nomo with realis mood, and gan in irrealis mood.

Another example involves person marking. While person is encoded by means of prefixes in the substrate languages, as the relevant markers are free forms in Kriol. The pronominal system of the substrate languages of Kriol distinguishes between singular, dual and plural, and furthermore between first person inclusive and exclusive. These distinctions are shown in 24.

24.

\begin{tabular}{|c|c|c|c|}
\hline & Singular & Dual & Plural \\
\hline 1 & $\sqrt{ }$ & & \\
\hline 2 & $\sqrt{1}$ & $\sqrt{1}$ & $\sqrt{ }$ \\
\hline 3 & $\sqrt{ }$ & $\sqrt{ }$ & $\sqrt{ }$ \\
\hline 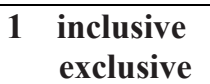 & & $\begin{array}{l}\sqrt{ } \\
\sqrt{ }\end{array}$ & $\begin{array}{l}\sqrt{ } \\
\sqrt{ }\end{array}$ \\
\hline
\end{tabular}

(adapted from Munro 2004:121)

These distinctions are reproduced in Kriol, as shown in 25 . 
25.

\begin{tabular}{|c|c|c|c|}
\hline & \begin{tabular}{|l} 
Singular \\
\end{tabular} & Dual & Plural \\
\hline 1 & $a i / m i$ & & \\
\hline 2 & $y u$ & yundubala & yumop \\
\hline 3 & im & dubala & olabat \\
\hline $1 \begin{array}{l}\text { inclusive } \\
\text { exclusive }\end{array}$ & & $\begin{array}{l}\text { yunmi } \\
\text { mindubala/minbala }\end{array}$ & $\begin{array}{l}\text { wi } \\
\text { melabat/mela }\end{array}$ \\
\hline
\end{tabular}

(adapted from Munro 2004:123)

In the substrate languages of Kriol, independent pronouns are used exclusively for emphasis or contrastive purposes (Munro 2004:120); in Kriol, on the other hand, independent pronouns are also used to encode person and number before the verb.

The above examples show that, even in the case of agglutinative substrate languages, the categories of the substrate languages are relabelled, either as bound forms or as free forms. In short, this case represents the situation in which relabelling applies to all lexical categories, and affixes are relabelled as either bound or free forms.

\section{Conclusion}

In this paper, I looked at language contact phenomena from the point of view of the processes at work in the creation of new language varieties rather than of the language varieties themselves. I concentrated on one process: relabelling. First, it was shown that this process is much more important and widespread than it appears at first glance. For one thing, several terms that are in use actually turn out to refer to this process. When such cases are in fact identified as cases of relabelling, the importance of the process is revealed. Second, it was shown that relabelling is used in a number of language contact situations: during the first stage of acquisition of a second language, in cases of full transfer by bilingual speakers, in the creation of mixed and creole languages, and in situations of language death. The extent of recourse to the process across various language contact situations attests to its importance. The second part of the paper considered the extent of relabelling across lexicons. It was shown that different situations correlate with different amounts of relabelling. The variable extent of its application across lexicons was shown to correlate with a number of factors that define the situations in which the process is used. These factors include the number of languages involved, the amount of access to the 'lexifier'/ 'target' $/ \mathrm{L}_{2}$ language, and whether code switching or language shift are involved. The third part of the paper considered extensive relabelling of agglutinative languages, showing that substrate language affixes may be relabelled either as affixes or as free forms.

The general approach taken in this paper shows that it possible to conduct a unified analysis of the contribution of a single process to the makeup of various language varieties arising in different language contact situations, and thus to link a number of contact phenomena and situations that would otherwise remain separate.

\section{References}

Allsopp, Richard. 1980. How does the creole lexicon expand? In Albert Valdman \& Highfield, Arnold (eds.), Theoretical Orientations in Creole Studies, 89-107. New York: Academic Press.

Andersen, Roger W. 1983. A language acquisition interpretation of pidginisation and creolisation. In Roger W. Andersen (ed.), Pidginisation and Creolisation as Language Acquisition, 1-59. Rowley, MA: Newbury House. 
Bakker, Peter. 1989. Relexification in Canada: The case of Métif (French-Cree). La créolisation, Claire Lefebvre \& Lumsden, John S. (eds.), 339-350. Special issue of the Revue canadienne de linguistique 34.3 .

Bakker, Peter. 1992. A language of our own: The genesis of Mitchif, the mixed Cree-French language of the Canadian Metis, Doctoral Dissertation, University of Amsterdam, Amsterdam. (1997) A language of our own': the genesis of Michif, the mixed Cree-French language of the Canadian Métis. Oxford: Oxford University Press.

Bakker, Peter. 1994. Michif, the Cree-French mixed language of the Métis buffalo hunters in Canada. In Peter Bakker \& Mous, Marteen (eds.), Mixed Languages. 15 Case Studies in Language Intertwining, 13-33. Dordrecht: ICG Printing.

Bakker, Peter \& Mous, Marteen (eds.). 1994. Mixed Languages. 15 Case Studies in Language Intertwining [Studies in Language and Language Use 13]. Dordrecht: ICG Printing.

Bao, Zhiming \& Lye, Huy Min. 2005. Systemic transfer, topic prominence, and the bare conditional in Singapore English. Journal of Pidgin and Creole Languages 20.2:269-291.

Bao, Zhiming \& Wee, Lionel. 1999. The passive in Singapore English. World Englishes 18.1:1-11.

Bao, Zhiming \& Wee, Lionel. 2005. The aspectual system of Singapore English and the systemic substratist explanation. Journal of Linguistics 41.2:237-267.

Boretsky, Norbert \& Igla, Birgit. 1994. Romani mixed dialects. In Peter Bakker \& Mous, Marteen (eds.), Mixed Languages. 15 Case Studies in Language Intertwining, 35-68. Dordrecht: ICG Printing.

Brousseau, Anne-Marie. \& Nikiema, Emmanuel. 2006. From Gbe to Haitian: The multi-stage evolution of syllable structure. In Claire Lefebvre, White, Lydia \& Jourdan, Christine (eds.), L2 Acquisition and Creole Genesis. Dialogues, 295-330. Amsterdam: John Benjamins.

Bruyn, Adrienne. 2003. Grammaticalisation, réanalyse et influence substratique: quelques cas du sranan. In Sibylle Kriegel (ed.), Grammaticalisation et réanalyse. Approches de la variation créole et française, 25-48. Paris: CNRS.

Detges, Ulrich. 2003. La notion de réanalyse et son application à la description des languages créoles. In Sibylle Kriegel (ed.), Grammaticalisation et réanalyse. Approches de la variation créole et française, 49-68. Paris: CNRS.

Hesseling, Dirk C. 1933. Een Spaans boek over het Papiaments, Tijdschrift voor Nederlandse taalen letterkunde (TNTL) 52:40-57; review of Rodolfo Lenz El Papiamento, la lengua criolla de Curazao (la gramática más sencilla), Anales de la Univ. de Chile, Separatum (Santiago, 1928).

Hill, Jane H. \& Hill, Kenneth C. 1977. Language death and relexification in Tlaxcalan Nahuatl. Journal of the Sociology of Language 12:55-69.

Keesing, Roger M. 1988. Melanesian Pidgin and the Oceanic Substrate. Stanford, CA: Stanford University Press. 
Koch, Harold. 2000. The role of Australian Aboriginal languages in the formation of Australian Pidgin grammar: Transitive verbs and adjectives. Processes of Language Contact. Studies from Australia and the South Pacific, Jeff Siegel (ed.), 13-46. Montreal: Fides.

Koopman, Hilda. 1986. The genesis of Haitian: Implications of a comparison of some features of the syntax of Haitian, French and West African languages. In Pieter C. Muysken \& Smith, Norval (eds.), Substrata Versus Universals in Creole Genesis, 231-258.

Kriegel, Sibylle (ed.). 2003. Grammaticalisation et réanalyse. Approches de la variation créole et française. Paris: CNRS.

Lafage, Suzanne. 1985. Français écrit et parlé en pays Ewé (Sud-Congo). Paris: SELAF.

Lardière, Donna. 2006. Comparing creole genesis with SLA in unlimited-access contexts: Going beyond relexification. In Claire Lefebvre, White, Lydia \& Jourdan, Christine (eds.), L2 Acquisition and Creole Genesis. Dialogues, 401-428. Amsterdam: John Benjamins.

Lefebvre, Claire. 1998. Creole genesis and the acquisition of grammar: The case of Haitian Creole [Cambridge Studies in Linguistics 88]. Cambridge: Cambridge University Press.

Lefebvre, Claire. 2002. The field of pidgin and creole linguistics at the turn of the millennium: The problem of the genesis and development of PCs. In Glenn G. Gilbert (ed.), Pidgin and Creole Linguistics in the Twenty-First Century, 247-287. New York: Peter Lang.

Lefebvre, Claire. 2003. The emergence of productive morphology in creole languages: The case of Haitian Creole. In Geert Booij \& van Marle, Jaap (eds.), Yearbook of Morphology 2002, 3581. Dordrecht: Kluwer.

Lefebvre, Claire. 2006. The contribution of relexification, grammaticalization, reanalysis, and diffusion to contact-induced language change. Presented at a special session on contactinduced change, Society for Pidgin and Creole Linguistics/Linguistic Society of America, Albuquerque.

Lefebvre, Claire \& Lumsden, John S. 1994. Relexification in creole genesis. The Central Role of Relexification in Creole Genesis: The Case of Haitian Creole. Research report prepared for SSHRCC on the project La genèse du créole haïtien: un cas particulier d'investigation sur la forme de la grammaire universelle, Claire Lefebvre \& Lumsden, John S. (eds.), 28 pages, Montreal: Université du Québec à Montréal.

Lefebvre, Claire, White, Lydia \& Jourdan, Christine (eds.). 2006. L2 Acquisition and Creole Genesis. Dialogues [Language Acquisition and Language Disorders 42]. Amsterdam: John Benjamins.

Leland, Charles G. 1874. The Gypsies and Their Language. London: Trübuer \& Co.

Lumsden, John S. 1999. Language acquisition and creolization. In Michel DeGraff (ed.), Language Creation and Language Change, 129-157. Cambridge - London: MIT Press.

Merlan, Francesca. 1983. Ngalakgan Grammar, Texts and Vocabulary. Canberra: Pacific Linguistics B/89.

Migge, Bettina. 2003. Creole Formation as Language Contact: The case of the Suriname Creoles [Creole Language Library 25]. Amsterdam: John Benjamins. 
Mous, Marteen. 1994. Ma'a or Mbugu. In Peter Bakker \& Mous, Marteen (eds.), Mixed Languages. 15 Case Studies in Language Intertwining, 175-200. Dordrecht: ICG Printing.

Mous, Marteen. 1995. Language intertwining. Paper read at the Amsterdam Creole Workshop: Creole Genesis and Language Contact, Amsterdam.

Mous, Marteen. 2001. Ma'a as an ethno-register of Mbugu. In Derek Nurse (ed.), Sprache und Geschichte in Afrika 16/17; Historical Language Contact in Africa, 293-320. Köln: Rüdiger Köppe.

Mufwene, Salikoko S. 1986. The universalist and substrate hypotheses complement one another. In Pieter C. Muysken \& Smith, Norval (eds.), Substrata Versus Universals in Creole Genesis, 129-162.

Mufwene, Salikoko S. 1990. Transfer and the substrate hypothesis in creolistics, Studies in Second Language Acquisition 12:1-23.

Munro, Jennifer M. 2000. Kriol on the move: A case of language spread and shift in Northern Australia. In Jeff Siegel (ed.), Processes of Language Contact. Studies from Australia and the South Pacific, 245-270.

Munro, Jennifer M. 2004. Substrate language influence in Kriol: The application of transfer constraints to language contact in Northern Australia. Doctoral Dissertation, University of New England.

Muysken, Pieter C. 1981. Half-way between Quechua and Spanish: The case for relexification. In Arnold Highfield \& Valdman, Albert (eds.), Historicity and Variation in Creole Studies, 52-79. Ann Arbor, MI: Karoma.

Muysken, Pieter C. 1988. Media Lengua and linguistic theory. The Canadian Journal of Linguistics 33:409-422.

Muysken, Pieter C. 2007. Mixed codes. Handbook of Bilingualism and Bilingual Communication, Peter Auer \& Wei, Li (eds.). The Hague: Mouton.

Muysken, Pieter C. \& Smith, Norval (eds.) 1986. Substrata Versus Universals in Creole Genesis [Creole Language Library 1]. Amsterdam / Philadelphia: John Benjamins.

Naro, Anthony J. 1978. A study of the origins of pidginisation. Language 54:314-347.

Papen, Robert. 1988. Convergence et divergence en métif. Paper read at the Department of Linguistics, Université du Québec à Montréal.

Rassinoux, Jean. 2000. Dictionnaire français-fon. Cotonou : Société des Missions africaines.

Ross, Malcolm. 2007. Calquing and metatypy. Journal of Language Contact, Thema 1:116-143. www.jlc-journal.org/.

Schuchardt, Hugo. 1979. The Ethnography of Variation: Selected Writings on Pidgins and Creoles, edited and translated by Thomas L. Markey. Ann Arbor, MI: Karoma.

Schwartz, Bonnie \& Sprouse, Rex. 1996. L2 cognitive states and the full transfer/full access model. Second Language Research 12.1:40-72. 
Sharpe, Margaret C. 1972. Alawa Phonology and Grammar. Canberra: Australian Institute of Aboriginal Studies.

Siegel, Jeff. 1995. Koine formation and creole genesis. Paper read at the Amsterdam Creole Workshop.

Siegel, Jeff (ed.). 2000. Processes of Language Contact. Studies from Australia and the South Pacific [Collection Champs linguistiques]. Montreal: Fides.

Siegel, Jeff. To appear. Mixing, levelling and pidgin/creole development. In Arthur Spears \& Winford, Don (eds.), Pidgins and Creoles: Structure and Status, Amsterdam: John Benjamins.

Sprouse, Rex. 2006. Full transfer and relexification: Second language acquisition and creole genesis. In Claire Lefebvre, White, Lydia \& Jourdan, Christine (eds.), L2 Acquisition and Creole Genesis. Dialogues, 169-182. Amsterdam: John Benjamins.

Steele, Jeffrey \& Brousseau Anne-Marie. 2006. Parallels in process: Comparing Haitian Creole and French learner phonologies. In Claire Lefebvre, White, Lydia \& Jourdan, Christine (eds.), L2 Acquisition and Creole Genesis. Dialogues, 331-354. Amsterdam: John Benjamins.

Terrill, Angela \& Dunn, Michael. 2006. Semantic transference: Two preliminary case studies from the Solomon Islands. In Claire Lefebvre, White, Lydia \& Jourdan, Christine (eds.), L2 Acquisition and Creole Genesis. Dialogues, 67-86. Amsterdam: John Benjamins.

Trask, Robert L. 1993. A Dictionary of Grammatical Terms in Linguistics. London - New York: Routledge.

Van Coetsem, Frans. 2000. A General and Unified Theory of the Transmission Process in Language Contact. Heidelberg: Universitätsverlag, C. Winter.

Weinreich, Uriel. 1953. Languages in Contact. The Hague: Mouton de Gruyter.

Winford, Don. 2008. Processes of creole formation and related contact-induced language change. (This volume). 